\title{
NEW DRUGS IN CLINICAL TRIALS FOR TREATMENT OF ALZHEIMER'S DISEASE
}

\author{
SOFKA', D. C. K.; CARNEIRO ${ }^{2}$, R. F. C.; PIETROVSKI ${ }^{3}$, E. F. \\ 1 - Aluna do Curso de Farmácia do Centro Universitário Campos de Andrade. \\ 2 - Professora Doutora em Farmacologia do Centro Universitário Campos de Andrade. \\ 3 - Professora Doutora em Farmacologia e Técnica no Instituto Federal do Paraná. \\ Email: evelisefernandes@gmail.com
}

\section{RESUMO:}

A Doença de Alzheimer (DA) é um transtorno neurodegenerativo crônico e progressivo manifestado por deterioração da memória e perda das funções cognitivas. Há várias hipóteses sobre as causas: perda do neurotransmissor acetilcolina (ACh), o depósito de peptídeo beta-amiloide formando as placas senis, os emaranhados neurofibrilares contendo a proteína TAU, mecanismos genéticos e inflamatórios. A atual farmacoterapia objetiva tratar sinais e sintomas gerados pela neurodegeneração. Portanto, objetivou-se apresentar os tratamentos farmacológicos que estão sendo avaliados em testes clínicos, que possam agir de maneira preventiva evitando a neurodegeneração irreversível. Também avaliar as drogas atuais com relação a efetividade e segurança do paciente. Entre os novos medicamentos podem ser citados: a terapia antiamilóide; agonista de receptor GLP-1R (GLP-1R), que promove a inibição da formação das placas senis; antagonistas do receptor histaminérgico H3, para aumento na liberação de ACh; o bexarotene, impede o acúmulo do beta-amilóide; os inibidores da enzima conversora angiotensina (IECA); vitaminas do complexo B, reduzem os níveis de homocisteína; as estatinas e os anti-inflamatórios. Apesar de vários medicamentos estarem em testes clínicos o tratamento da DA ainda é um desafio, uma vez que não se sabe como se inicia, dificultando a reversão da neurodegeneração e, consequentemente, os sintomas decorrentes.

Palavras-chave: Doença de Alzheimer, Farmacologia, Avaliação de Medicamentos.

\begin{abstract}
:
Alzheimer's disease (AD) is a chronic and progressive neurodegenerative disorder manifested by memory impairment and loss of cognitive functions. There are several hypotheses about the causes: loss of the neurotransmitter acetylcholine (ACh), deposition of beta-amyloid peptide forming senile plaques, neurofibrillary tangles containing TAU protein, genetic and inflammatory mechanisms. The current pharmacotherapy aims to treat signs and symptoms generated by neurodegeneration. Therefore, this study aimed to present the pharmacological treatments being evaluated in clinical trials, which can act preventively avoiding irreversible neurodegeneration. Also evaluate current drugs with respect to effectiveness and patient safety. Among the new drugs can be cited: antiamilóide agonist therapy; GLP-1R receptor agonist (GLP$1 \mathrm{R})$, which promotes inhibition of the formation of senile plaques; the histaminergic $\mathrm{H} 3$ receptor antagonists, to increase ACh release; bexarotene, prevents the accumulation of beta-amyloid; angiotensin-converting enzyme inhibitors (ACEI); B vitamins, reduce homocysteine levels; statins and anti-inflammatories. Although several drugs are in
\end{abstract}


clinical trials the treatment of AD is still a challenge, since it does not know how to start, difficult to reverse the neurodegeneration, and consequently the resulting symptoms.

Keywords: Alzheimer Disease, Pharmacology, Drug Evaluation.

\section{INTRODUÇÃO}

A Doença de Alzheimer (DA) é um transtorno neurodegenerativo crônico e progressivo manifestado por deterioração da memória e perda significativa das funções cognitivas, que acomete principalmente pacientes idosos, tendo como sua principal característica a demência (Araujo \& Pondé, 2006). Esta doença causa diminuição da memória, dificuldade no raciocínio e pensamentos, e, em estágios avançados há uma série de distúrbios comportamentais, fisiológicos e psiquiátricos envolvidos que podem levar a demência total (Sayeg, 2012).

A incidência da DA vem crescendo com o passar dos anos de forma alarmante, sendo a forma mais comum de demência, atingindo cerca de $0,6 \%, 1,0 \%, 2,0 \%$ e 3,3\% e $8,4 \%$ da população entre as idades de 65-69, 70-74, 75-79, 80-84 e 85, respectivamente, sendo que a prevalência também aumenta exponencialmente com a idade, passando de $3 \%$ entre os $65-74$ anos, para quase $50 \%$ entre os mais de 85 anos (Gutierrez et al., 2014). Além disso, é a quarta causa de morte nos países desenvolvidos (Inouye \& Oliveira, 2004).

Descoberta pelo médico psiquiatra neurofisiologista alemão Alois Alzheimer, em 1906, o qual acompanhou o tratamento da paciente Auguste Deter, de 51 anos, e após sua morte, quatro anos depois do início do tratamento, ele pode estudar seu cérebro. Nesse estudo ele observou atrofias generalizadas no córtex cerebral, camada responsável pelas habilidades intelectuais. Essas alterações já haviam sido observadas em cérebros de pacientes com demência, no entanto, em quantidades maiores e mais acentuadas no hipocampo, região importante na formação da memória (Forlin, 2013).

As causas da DA não são totalmente esclarecidas, mas uma das teorias para a doença seria a perda do neurotransmissor acetilcolina. Com a perda das sinapses surgem outras duas hipóteses histopatológicas que são a deposição do peptídeo betaamiloide, formando as placas senis, e a formação de emaranhados neurofibrilares contendo a proteína TAU (Guzen \& Cavalcanti, 2012).

Os tratamentos farmacológicos existentes atualmente visam reverter processos patofisiológicos que levem a neurodegeneração e a demência. Esses medicamentos conseguem promover um alívio dos sintomas decorrentes por um determinado período de tempo. Uma das principais classes de medicamentos utilizadas são os inibidores da colinesterase, também conhecidos como anticolinesterásicos, que inibem as enzimas acetilcolinesterase e butirilcolinesterase (Forlenza, 2005). A Tacrina ${ }^{\circledR}$ foi o primeiro anticolinesterásico utilizado para o tratamento da DA, no entanto, em decorrência do seu 
elevado índice de toxicidade caiu em desuso. Os anticolinesterásicos de segunda geração são a rivastigmina, a galantamina e o donepezil, que apesar de apresentarem alguns efeitos adversos foram tolerados pelos pacientes (FORLENZA, 2005).

Outra opção farmacológica seria a utilização da memantina que pode ser associada aos anticolinesterásicos sem ocorrer interações medicamentosas. Esta droga é um antagonista não-competitivo dos receptotes N-metil-D-aspartato (NMDA), bloqueia os efeitos elevados de glutamato, um importante aminoácido excitatório, que, em altos níveis e por um período prolongado, pode causar morte neural (ARAUJO \& PONDÉ, 2006).

Adicionalmente, existem outras abordagens terapêuticas que, segundo estudos, podem ter efeitos relevantes sobre a DA, como os antioxidantes, estrógenos, anti-inflamatórios não hormonais, estatinas e ginkgo-biloba. Contudo, os efeitos dessas classes terapêuticas se limitam ao retardamento evolutivo da neurodegeneração de forma reversível, ou seja, uma melhora temporária dos sintomas (FORLENZA, 2005).

Portanto, com relação ao tratamento farmacológico da DA, embora existam poucas classes terapêuticas atualmente disponíveis novas drogas estão sendo testadas pela indústria farmacêutica em testes clínicos (ASHRAF et al., 2015).

Com isso se torna muito importante avaliar as novas drogas que possivelmente estarão disponíveis futuramente, visto que a maioria dos tratamentos atuais não reverte a neurodegeneração, apenas promove um alívio temporário dos sintomas (ASHRAF et al., 2015). Dessa forma, pretendeu-se verificar as novas drogas avaliadas em estudos clínicos, bem como avaliá-las em relação a efetividade e segurança. Dentro desse contexto, o presente estudo abordou, primeiramente, a fisiopatologia da DA para, posteriormente, contextualizar com os possíveis mecanismos de ação dos novos medicamentos em testes clínicos para o Mal de Alzheimer, priorizando a busca por novos medicamentos que possam agir de maneira preventiva evitando a neurodegeneração irreversível.

\section{METODOLOGIA}

Trata-se de um estudo de revisão, quanto a abordagem metodológica qualitativa sendo utilizados artigos científicos, por meio de busca eletrônica em base de dados como Google Acadêmico, Scielo Brasil, Periódicos Capes e Biblioteca Digital Brasileira de Teses e Dissertações.

A amostra seguiu os seguintes critérios: o estudo foi realizado utilizando publicações de qualquer país do mundo, sem restrição de idiomas, obtidos na integra em um período compreendido a partir do ano de 2000 até 2014. Os descritores utilizados nas pesquisas foram "Alzheimer", "testes clínicos" e "tratamento". 


\subsection{Fisiopatologia}

Existem várias teorias sobre as causas da DA as principais são a perda do neurotransmissor colinérgico, a deposição do peptídeo beta-amiloide formando as placas senis, a formação de emaranhados neurofibrilares contendo a proteína TAU, mecanismos genéticos e inflamatórios (CAVALCANTI, ENGELHARDT, 2012). Os emaranhados neurofibrilares (ENF) e as placas senis estão frequentemente presentes em tecidos cerebrais de pacientes portadores da DA. Os ENF são agregados formandos pela proteína TAU, a qual é fisiologicamente importante na estabilização dos microtúbulos do citoesqueleto neuronal (MONTEIRO et al,2011). Em algumas condições patológicas, como a DA, ocorre uma hiperfosforilação da proteína TAU e isso altera a sua solubilidade, reduz a afinidade tubulina, instabilizando a estrutura do citoesqueleto microtubular e causando a morte celular (PAULA, et al., 2009) (TABELA 1).

TABELA 1 - Tabela explicativa sobre as hipóteses histopatológicas e seus mecanismos.

\begin{tabular}{|c|c|}
\hline Teoria histopatológica & Mecanismo \\
\hline Hipótese colinérgica & $\begin{array}{c}\text { Diminuição da síntese do neurotransmissor acetilcolina } \\
\text { ou degradação pela enzima acetilcolinesterase ou } \\
\text { butirilcolinesterase }\end{array}$ \\
\hline Mecanismo genética & $\begin{array}{c}\text { Genes que codificam proteínas que podem ser } \\
\text { responsáveis pela formação do beta-amilóide ou altera } \\
\text { a fosforilação da proteína TAU }\end{array}$ \\
\hline Cascata beta-amilóide & $\begin{array}{c}\text { Forma-se pela clivagem da proteína precursora amilóide } \\
\text { pelas enzimas secretases gama e beta }\end{array}$ \\
\hline $\begin{array}{l}\text { Emaranhados neurofibrilares contendo a } \\
\text { proteína TAU }\end{array}$ & $\begin{array}{l}\text { Ocorre uma anormalidade a hiperfoforilação da proteína } \\
\text { TAU }\end{array}$ \\
\hline Mecanismo inflamatório & $\begin{array}{l}\text { Inibir a enzima ciclooxigenase, e assim inibir a resposta } \\
\text { inflamatória }\end{array}$ \\
\hline
\end{tabular}

Fonte: O AUTOR e adaptado de: CAVALCANTI, ENGELHARDT, 2012; HUEB, 2008; SASTRE, KLOCKGETHER, HENEKA, 2006; OJOPI, BERTONCINI, NETO, 2004.

Na hipótese de comprometimento colinérgico o neurotransmissor colinérgico, a acetilcolina, é liberado através das sinapses neuronais, sendo um dos neurotransmissores responsáveis pelo comportamento e emoções do paciente (CLARK et al, 2013). O prosencéfalo basal é afetado precocemente na DA incluindo perda de neurônios colinérgicos, isto significa, que o nível de acetilcolina está diminuído (Pereira, 2013). Adicionalmente, além da produção de 
acetilcolina estar reduzida, em decorrência da perda neuronal, sua degradação pela enzima acetilcolinesterase pode estar excessivamente aumentada (PEREIRA, 2013). Este neurotransmissor é o principal responsável pela formação da memória e está relacionado com funções cognitivas. Entretanto, a DA promove a degeneração de vários sistemas de neurotransmissores como serotonina, glutamato e neuropeptídeos (HUEB, 2008).

O componente hereditário tem se mostrado relacionado ao desenvolvimento da DA. Os estudos genéticos demonstram que a DA pode ocorrer com maior frequência em determinadas famílias, e que pacientes portadores da DA tem $50 \%$ de chance de seus filhos terem a doença (SERENIKI, VITAL, 2008).

A DA foi associada a mutação de genes que codificam a proteína precursora amiloide (PPA), os quais estão localizados no braço longo do cromossomo 21 e são responsáveis pela formação de beta-amilóide. O gene presenilina 1 no cromossomo 14 está envolvida na regulação e fosforilação da proteína TAU, essas mutações são responsáveis por cerca de $40 \%$ dos casos de DA precoces. O gene responsável pela DA esporádica é a presenilina 2 no cromossomo 1, esta também forma o peptídeo betaamilóide (SMITH, 1999). Porém, 95\% da doênça ocorre com início tardio, no qual já foram descritos muitos marcadores genéticos. Um destes é o gene apolipoproteina $E$ (Apo E) que possui três principais fenótipos, os alelos E2, E3 e o E4, mas somente o polimorfismo do gene Apo E alelo 4 no cromossomo 19 mostrou uma associação consistente quanto ao número de placas senis, além de uma redução da função colinérgica de pacientes portadores da DA. Índices apontam que o alelo 4 é encontrado em apenas $14 \%$ da população sendo que entre $34 \%$ a $65 \%$ dos pacientes com DA apresentam o polimorfismo (OJOPI et al., 2004).

A apoliproteina E está localizada no braço longo do cromossomo 19 e é uma das principais proteínas presentes no plasma humano responsável pelo transporte de lipídios e outros fluidos corpóreos, estando diretamente relacionada com o colesterol. A apoE primeiramente é sintetizada pelo fígado, o segundo responsável por sua síntese é o cérebro sendo produzida principalmente nos astrócitos e micróglia. Estudos comprovam o papel específico da apoE 4 na formação de placas amiloides e emaranhados neurofibrilares (ENF), a apoliproteina promove a fibrilogênese da proteína beta-amiloide e quando se expressa no interior dos neurônios altera a fosforilação da proteína TAU levando a formação dos ENF (OJOPI et al., 2004).

O peptídeo beta-amiloide é um fragmento peptídico formado pela clivagem da proteína precursora amiloide (PPA). A PPA pode ser clivada pelas enzimas secretases alfa, beta ou gama. Quando a PPA é clivada pela enzima secretase alfa forma uma proteína não amiloidogênica que tem função protetora neural. Na clivagem pelas secretases beta e gama forma-se um composto amiloidogênico, os peptídeos betaamiloide, que causam neurotoxicidade. Estes peptídeos formam pequenos agregados 
como oligômeros solúveis e fibrilas insolúveis que se agregam formando as placas senis (CAVALCANTI , ENGELHARDT, 2012).

A formação de emaranhados neurofibrilares contendo a proteína TAU são responsáveis pela perda neuronal e perda sináptica que se relacionam com progressão do declínio cognitivo. Como mencionado anteriormente, em condições fisiológicas a proteína TAU é responsável pela estabilização e sustentação dos microtúbulos e também desempenha um papel na comunicação e formação celular. Ocorre uma anormalidade quando ela é hiperfosforilada se dissociando dos microtúbulos e se agregando sob formas de filamentos helicoidais insolúveis e estes nos emaranhados neurofibrilares (CAVALCANTI , ENGELHARDT, 2012).

Há evidências que a DA está associada com uma resposta inflamatória local, que é iniciada através da ativação das principais células envolvidas no mecanismo de resposta inflamatória no sistema nervoso central os astrócitos e a micróglia. Estas células são encontradas em abundância perto de neurônios e placas danificadas, quando ativadas liberam uma variedade de mediadores inflamatórios, tais como citocinas e produtos neurotóxicos que podem contribuir para a degeneração neuronal e morte celular (SASTRE et al., 2006).

$\mathrm{Na}$ DA o número de astrócitos encontra-se elevado, bem como a atividade da enzima fosfolipase $\mathrm{A} 2\left(\mathrm{PLA}_{2}\right)$, esta pertence a uma família que catalisam a clivagem de ácidos graxos. Há mais de 19 isoformas diferentes de $\mathrm{PLA}_{2}$ mas estudos recentes têmse centrado em três grupos principais: a cPLA ${ }_{2}$ citosólica dependente de cálcio grupo

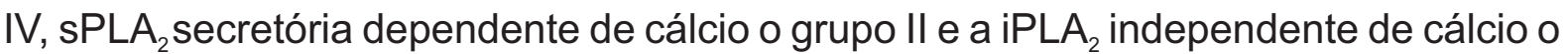
grupo VI. Estes $\mathrm{PLA}_{2}$ s estão envolvidas na liberação do ácido araquidônico $(A A)$ e a síntese de eicosanoides, na liberação de agentes oxidantes e citocinas inflamatórias (SUN et al., 2004).

\section{NOVOS MEDICAMENTOS EM TESTES PRÉ-CLÍNICOS E CLÍNICOS}

Entre os novos medicamentos podem ser citados: a terapia antiamilóide sendo que sua função pode ser brevemente descrita como a inibição das placas senis; os antihistamínicos H3, que aumentam a liberação de neurotransmissores e o bexarotene, com a função de limpeza tecidual impedindo o acúmulo de beta-amiloide. Adicionalmente, pode-se mencionar os inibidores da enzima conversora de angiotensina (IECA), que tem uma relação a uma taxa lenta do declínio cognitivo; receptor de GLP-1 (GLP-1R), agonista liraglutida, no qual a ideia seria diminuir os acúmulos beta-amiloides; vitaminas do complexo B que pretende diminuir o nível de homocisteina; estatinas, na qual a função é diminuir o nível plasmático de colesterol e assim a formação de beta-amiloide, e os anti-inflamatórios, que segue como pressuposto o mecanismo anti-inflamatório (TABELA2). 
TABELA 2 - Relação dos novos medicamentos em testes e seus respectivos mecanismos de ação.

\begin{tabular}{|c|c|c|c|}
\hline Medicamento & Mecanismo de ação & Tipo de Teste & Fase do teste \\
\hline $\begin{array}{l}\text { clioquinol (iodocloro- } \\
\text { hidroxiquina) }\end{array}$ & $\begin{array}{l}\text { Terapia antiamiloide - } \\
\text { inibidores da fibrilogênese }\end{array}$ & Teste clínico & Fase II \\
\hline Composto NC-531 & $\begin{array}{l}\text { Terapia antiamiloide- } \\
\text { inibidores da fibrilogênese }\end{array}$ & Teste clínico & Fase II \\
\hline Levofloxacino & $\begin{array}{l}\text { Terapia antiamiloide- } \\
\text { inibidores da fibrilogênese }\end{array}$ & Teste pré-clínico & Pré-clínico \\
\hline Semagacest & $\begin{array}{l}\text { Inibidores da formação do } \\
\text { peptídeo beta-amiloide }\end{array}$ & Teste clínico & Fase II \\
\hline Composto AN-1792 & $\begin{array}{l}\text { Promotores da depuração do } \\
\text { beta-amiloide }\end{array}$ & Teste clínico & Fase II \\
\hline $\begin{array}{l}\text { Imunoglobulina } \\
\text { intravenosa }\end{array}$ & $\begin{array}{l}\text { Promotores da depuração de } \\
\text { beta-amilóide }\end{array}$ & Teste clínico & Fase II \\
\hline $\begin{array}{l}\text { Compostos GSK- } \\
\text { 239512, MK-0249, ABT- } \\
\text { 288, PF-03654746 }\end{array}$ & $\begin{array}{l}\text { Antagonistas do receptor } \\
\mathrm{H}_{3} \mathrm{R}\end{array}$ & Teste clínico & Fase II \\
\hline Bexarotene & $\begin{array}{l}\text { Agonista dos receptores } \\
\text { retinoides } X(R X R)\end{array}$ & Teste pré-clínico & Pré-clínico \\
\hline $\begin{array}{l}\text { Inibidores da enzima } \\
\text { conversora } \\
\text { angiotensina (IECA) }\end{array}$ & $\begin{array}{l}\text { Inibe angiotensina II que tem } \\
\text { efeito inibitório sobre o } \\
\text { sistema colinérgico }\end{array}$ & Teste clínico & Fase II \\
\hline $\begin{array}{l}\text { Receptor de (GLP-1R): } \\
\text { agonista liraglutida }\end{array}$ & $\begin{array}{l}\text { Libera AMPc nos neurônios } \\
\text { e liberam } \\
\text { neurotransmissores }\end{array}$ & Teste clínico & Fase II \\
\hline $\begin{array}{l}\text { Vitaminas do complexo } \\
\text { B }\end{array}$ & $\begin{array}{l}\text { Baixar os níveis de } \\
\text { homocisteina sanguíneos }\end{array}$ & Teste clínico & Fase II \\
\hline Estatinas & $\begin{array}{l}\text { Diminuir a formação do } \\
\text { peptídeo beta-amiloide }\end{array}$ & Teste clínico & Fase I \\
\hline $\begin{array}{l}\text { Anti-inflamatórios } \\
\text { esteroidais e não } \\
\text { esteroidais }\end{array}$ & Inibir a ciclooxigenase & Teste clínico & Fase II \\
\hline
\end{tabular}

Fonte: O AUTOR e adaptado de: DOODY et al., 2013; DOUAUD et al., 2013; CRAMER et al., 2012; PINTO, 2012; EGEFJORD et al., 2012; BRUCKI et al., 2011; REIS et al., 2012; TUERO, 2009; SERENIKI, VITAL, 2008; FORLENZA, 2005. 


\subsection{Terapia antiamilóide}

Terapia antiamilóide segue como pressuposto teórico a hipótese da cascata amiloide, considerada a teoria central da etiologia da DA. De acordo com essa teoria, a deposição da proteína beta-amilóide formando as placas senis e a hiperfosforilação da proteína TAU formando os emaranhados neurofibrilares comprometem a função neuronal, levando a morte neuronal, especificamente de neurônios colinérgicos, consequentemente ocasionando déficit do neurotransmissor acetilcolina. Os fármacos com terapia antiamilóide podem ser divididos em três categorias: A) inibidores da fibrilogênese, B) Inibidores da formação do peptídeo beta amilóide e C) promotores da depuração de beta-amilóide.

\section{A) Inibidores da fibrilogênese:}

A fibrilogênese pode ser entendida como uma reação de duas etapas, a primeira no estado nativo da proteína e a segunda em um estado fibrilar. Há uma conformação da proteína que se funde progressivamente, sendo pré-disposta a agregação. A fibrilogênese do peptídeo beta-amilóide seria a agregação da proteína beta-amiloide em formas solúveis (LOBATO, 2004).

Na categoria inibidores da fibrinogênese do peptídeo beta-amilóide encontramse o quelante de metais clioquinol (iodocloro-hidroxiquina) e o NC- 531, que tem como função a propriedade de reduzir a transformação de formas solúveis da beta-amilóide em polímero beta-pregueados insolúveis (FORLENZA, 2005).

O NC-531, é uma molécula orgânica de baixo peso molecular que tem como mecanismo de ação a inibição da fibrilogênese e a remoção das formas solúveis de beta-amilóide, prevenindo sua deposição em tecidos cerebrais e os eventos da cascata amilóide. Em estudos clínicos de fase III o NC-531 demonstrou ser bem tolerado e reduziu a concentração da proteína beta-amilóide no líquido cefalorraquidiano (FORLENZA, 2005).

O Clioquinol (iodocloro-hidroxiquina) é um antibiótico que tem a capacidade de quelar íons de metais pesados como cobre, ferro e zinco inibindo a agregação do peptídeo beta-amilóide. Há evidências de que a interação desses íons com a proteína beta-amilóide pode estar relacionada com a formação e maturação das placas senis, pois esses metais se agregam as fibras amilóidais insolúveis formando um composto neurotóxico (BRUCKl et al., 2011).

Alterações da homeostase do cobre, ferro e zinco foram identificados na DA, o que significa que o manuseio incorreto desses metais pode ser considerado um fator de risco para a doença. Por essas razões, os quelantes de metais oferecem um potencial terapêutico para a patogenia da DA. Sendo assim, estudos mostraram que os quelantes 
de metais foram capazes de solubilizar essas fibras do peptídeo beta-amilóide em amostras de tecido pós mortem de pacientes com a DA (Regland et al., 2001). Em estudos utilizando camundongos houve uma redução no acúmulo do beta-amilóide. Estudos clínicos de fase II demonstraram uma redução do acúmulo de beta-amilóide plasmático e uma menor taxa de declínio cognitivo em pacientes tratados com clioquinol. No entanto, esses estudos foram interrompidos, pois o Clioquinol causou uma toxicidade rara e grave: a neuropatia mielo-óptica subaguda. Atualmente um derivado de Clioquinol está em teste clínico de fase II (BRUCKI et al., 2011).

Ainda entre os inibidores da fibrinogênese pode-se citar estudos relacionados ao antimicrobiano Levofloxacina, que segundo a literatura atuaria como um quelante metálico. Em testes realizados in vitro, por análises de fluxometria, o fármaco mostrouse capaz de inibir a formação de fibrilas do peptídeo beta-amilóide (REIS et al., 2012).

\section{B) Inibidores da formação do peptídeo beta-amilóide:}

Estes fármacos vão agir inibindo as enzimas proteolíticas secretases gama e beta, impedindo a clivagem da proteína precursora amiloide (PPA) e assim diminuindo a formação da proteína beta-amilóide. Foram realizados estudos sobre a inibição da secretase gama, analisando o fármaco Semagacest nas dosagens de $100 \mathrm{mg}$ e 140 mg, mas a experimentação foi descontinuada pela Food and Drugs Adminstration (FDA), pois os pacientes tratados com esse fármaco apresentaram efeitos adversos moderados a grave, como perda de peso e aumento do risco de câncer de pele e infecções (DOODY et al., 2013).

\section{C) Promotores da depuração de beta-amilóide:}

A teoria da remoção da proteína amilóide se baseia na imuno terapia, na qual seria criada uma vacina que estimulasse o sistema imune a combater a proteína betaamilóide e, assim, a formação das placas senis. Foi criada uma imunização ativa utilizando um antígeno específico para o beta-amilóide com o composto AN-1792. Os testes pré-clínicos em camundongos foram bem sucedidos, mas os testes de fase $\mathrm{Il}$ em humanos causaram meningoencefalite em $6 \%$ dos pacientes tratados e os testes de imunoterapia com este composto foram suspensos (FORLENZA, 2005).

Exemplos de imunoterapia passiva incluem imunoglobulina intravenosa com Bapineuzumab, solanezumab e Ponezumab. Este último visando especificamente a extremidade C-terminal (AA33-40) da proteína beta-amilóide, ao passo que alvos extremidade $\mathrm{N}$ - terminal (AA1-5), como bapineuzumab e solanezumab, reconhecem e ligam-se a uma sequência peptídica interior (AA16 -24). Estudo realizado com pacientes com DA leve a moderada, com esta terapia foram tratados em dose única por 
infusão intravenosa de 2 horas de 0,1 a $10 \mathrm{mg} / \mathrm{kg}$. Estudos clínicos de fase III demonstraram que a droga não atingiu seu objetivo terapêutico e seus testes foram descontinuados (LANDEN et al., 2013).

\subsection{Anti-histamínicos $\mathrm{H}_{3}$}

Há estudos sobre novas terapias como os antagonistas do receptor $\mathrm{H}_{3} R$. O receptor $\mathrm{H}_{3}$ é um autoreceptor inibitório, o que significa que a histamina quando estimula este receptor promove uma diminuição da sua própria liberação. $\mathrm{O}$ receptor $\mathrm{H}_{3}$ também é um heteroreceptor, quando estimulado diminui a histamina e com isso a liberação de outros neurotransmissores, como acetilcolina. Portanto, um antagonista $\mathrm{H}_{3} \mathrm{R}$ promove a liberação de histamina e com isso outros neurotransmissores, como a acetilcolina, dopamina, noradrenalina e serotonina (PINTO, 2012). Esses neurotransmissores ativam uma série de cascatas pós-sinápticas que por sua vez ativam um fator de transcrição, o CREB, que faz a transcrição de genes importantes na plasticidade sináptica e funções cognitivas. Estudos sobre vários antagonistas $\mathrm{H}_{3} R$, como os compostos GSK-239512, MK-0249, ABT-288, PF-03654746, foram bem tolerados nos primeiros testes em humanos e estão sendo iniciados testes clínicos de fase II. Esses compostos podem ser associados a anticolinesterásicos para melhorar a eficácia do tratamento (PINTO, 2012).

\subsection{Bexarotene}

Bexarotene é utilizado no tratamento de pacientes com linfoma cutâneo de células $T$ e pertence à classe dos retinóides derivados da vitamina $A$. Estudos recentes tem sugerido que a DA não decorre de um aumento no número de proteínas betaamilóide, mas sim, um problema no apuramento da solubilização deste peptídeo, pois o peptídeo beta-amilóide é produzido em níveis normais em pacientes com DA. Essas evidências apontaram que deveria se agir sobre o mecanismo de limpeza e não sobre a formação beta-amilóide (CRAMER et al., 2012).

O fármaco Bexarotene é agonista dos receptores retinoides $X(R X R)$, e ao ativar o receptor $\mathrm{RXR}$ aumenta a expressão da apolipoproteina apoE, ativa os transportadores de lipídeos e a secreção de partículas HDL, e desta maneira facilita a remoção das partículas solúveis de beta-amilóides. Além disso, com a estimulação dos receptores $\mathrm{RXR}$ há ativação dos macrófagos e micróglia que promovem a fagocitose. Os testes em camundongos revelaram que a utilização do fármaco Bexarotene aumentou a expressão da apoE resultando em um apuramento da solubilização das placas, que chegou a atingir $50 \%$ de melhora em relação as placas senis e funções cognitivas, melhorando assim a função do circuito neural (CRAMER et al., 2012). 
A expressão da apoE é induzida pela ação dos receptores nucleares receptores ativados por proliferador de peroxissomo (PPAR), o fígado $X$ (LXR) em coordenação com os receptores retinoides $X(R X R)$ esta atua normalmente como um suporte para a formação de HDL, promovendo a degradação proteolítica de formas solúveis de beta-amilóide (CRAMER et al., 2012).

\subsection{Inibidores da enzima conversora angiotensina (IECA)}

Foram realizados estudos de pacientes com a DA leve a moderada, que faziam uso contínuo ou intermitente de anti-hipertensivos (IECA) comparado com os pacientes que não fazem uso de qualquer anti-hipertensivo. Os IECAs diminuem os níveis de angiotensina II e diminuem, desta forma, a pressão arterial. O mecanismo de ação na DA, no qual esta teoria está baseada, é que os níveis elevados de angiotensina II exercem um efeito inibitório sobre o sistema colinérgico, sendo assim, quando utilizado um anti-hipertensivo IECA, além de benefícios na hipertensão, devido a diminuição da concentração de angiotensina II, há liberação do neurotransmissor acetilcolina, ocasionando melhora na DA (TUERO, 2010).

Os autores concluíram que a utilização de IECA em adultos idosos com DA pode aumentar os níveis do neurotransmissor acetilcolina que está associado a uma taxa mais lenta de declínio cognitivo e com isso há uma melhora da memória, independente da hipertensão. Pesquisas futuras são necessárias para explorar o papel da IECAna DA(SOTO et al., 2013).

\subsection{Receptor de GLP-1 (GLP-1R): Agonista liraglutida}

O diabetes mellitus tipo 2 (DM-2) aumenta o risco de desenvolver a DA e pacientes com DA são mais propensos a desenvolver DM-2. Há uma prematura degeneração celular em ambas as doenças, com isso foi testada a hipótese que o tratamento com o agonista do receptor de ação prolongada de GLP- 1, liraglutida, afeta o acúmulo de beta-amilóide em pacientes com DA, sendo que este fármaco é utilizado para o tratamento de diabetes (EGEFJORD et al., 2012). O receptor de GLP-1 induz o crescimento neuronal e protege os neurônios da morte celular, e também lesão oxidativa induzida pelas placas. O mecanismo consiste na liberação de AMPc, que, no pâncreas, libera insulina, mas nos neurônios liberam neurotransmissores, principalmente o glutamato. O efeito colateral mais comum relatado em pacientes tratados com liraglutida são os distúrbios gastrointestinais, principalmente náusea leve a moderada, mas somente nas primeiras semanas período de aplicação da liraglutida. Os testes feitos em ratos demostraram que a estimulação GLP-1R conseguiu diminuir os depósitos de placas beta-amilóides, o que resultou em crescimento de neurites e protegeu contra a apoptose das células nervosas, consequentemente proporcionando aumento de sua função cognitiva. Este estudo ainda está em testes clínicos de fase II (EGEFJORD et al., 2012). 


\subsection{Vitaminas do COMPLEXO B}

A homocisteína, um homólogo do aminoácido natural cisteína, é um aminoácido tóxico existente no sangue que pode causar danos nas artérias, no coração e cérebro. Níveis elevados de homocisteína têm sido relacionados aos danos cognitivos e a DA. Deste modo, uma abordagem terapêutica seria reduzir os níveis de homocisteína usando as vitaminas do complexo B, o que poderia melhorar a atrofia da matéria cinzenta, retardando assim o declínio cognitivo. Um teste clínico de fase II relatou que a suplementação de vitamina $\mathrm{B}$ pode retardar a atrofia de regiões específicas do cérebro que são o componente chave do processo da DA e que estão associados com o declínio cognitivo, mas somente em pacientes com a homocisteína elevada (DOUAUD et al., 2013).

\subsection{Estatinas}

Estudos clínicos de fase I demonstraram que os níveis plasmáticos de colesterol estão relacionados com a DA, pois há hipótese que o colesterol é capaz de regular o processo proteolítico da APP. De acordo com essa teoria quanto maior for o nível plasmático de colesterol maior será a probabilidade de formação dos peptídeos beta-amilóide. Inversamente, quando se reduz os níveis plasmáticos de colesterol também há uma redução na formação do peptídeo beta-amilóide. Um dos motivos seria o transportador de lipídeos, o gene apolipoproteina, o qual atua normalmente como um suporte para formação e segregação de partículas de HDL, e assim, facilita e remoção das partículas solúveis do beta-amilóide. Medicamentos à base de estatinas como lovastatina, sinvastatina, atorvastatina e pravastatina são responsáveis por essa proteção neuronal na DA(SERENIKI, VITAL, 2008).

\subsection{Anti-inflamatórios}

Com base na hipótese de que os processos inflamatórios estão envolvidos na DA, foram realizadas pesquisas sobre os anti-inflamatórios não-esteroidais e esteroidais no tratamento da doença. Sobre os anti-inflamatórios não-esteroidais (AINES) os estudos sugerem que a ciclooxigenase-2 (COX-2) está envolvida diretamente com a DA, por isso os medicamentos que inibem a COX-2 vão atuar bloqueando a formação de beta-amilóide. O ibuprofeno, indometacina e ácido acetilsalicílico, segundo estudos de cultura em células, reduziram em $80 \%$ a formação beta-amilóide. Inibidores da COX-1 se mostraram mais resistentes em relação a COX-2 (ENGELHARDT et al., 2005). No entanto, os resultados de estudos randomizados, duplo cego e placebo controlado não foram satisfatórios, pois os anti-inflamatórios não 
reduziram o declínio cognitivo induzido pela DA. Anti-inflamatórios esteroidais tinham sido descritos como agentes potentes, pois atuariam inibindo a ação das enzimas que mediariam a produção da COX e reduzindo as ações pró-inflamatórias, mas essa teoria foi descartada após testes randomizados e placebo-controlado que não demonstraram diferença entre o grupo tratado e o controle, afirmando que não reduziram o declínio cognitivo (SERENIKI , VITAL, 2008).

\section{UM NOVO PASSO NO DIAGNOSTICO BIOMARCADORES PARA A DA}

\subsection{Fosfoslipídeos na identificação da DA}

O tratamento da DA ainda é um desafio, talvez isso esteja relacionado ao fato que não se consegue identificar a doença antes que haja uma progressão que acarreta em perda de memória e o declínio cognitivo. Por isso, segundo estudos recentes, foi descoberto um exame sanguíneo que valida dez lipídeos como biomarcadores, estes podem prever um leve comprometimento cognitivo ou a DA dentro de um prazo de 2-3 anos com uma precisão superior a 90\% (MAPSTONE et al., 2014).

A análise foi focada num conjunto de dez metabólitos e biomarcadores lipídicos constituídos em espécies de fosfatidilcolina (PCs) e taurina e acilcarnitina (ACs). Estes são fosfolipideos que tem papéis estruturais e funcionais essenciais para o funcionamento e integridade das membranas celulares. Este estudo demonstrou a diminuição no nível plasmático de fosfatidilcolina e o aumento deste no fluido cerebroespinhal e de seus metabólitos em pacientes com a DA, bem como uma diminuição de fosfatidilinositol no hipocampo e outras regiões corticais. Além disso, o peptídeo beta amilóide pode perturbar diretamente a integridade da bicamada, interagindo com os fosfolipídios (MAPSTONE et al., 2014).

A taurina e acilcarnitina (ACs) são conhecidas como tendo um maior papel no metabolismo lipídico que ocorre dentro da mitocôndria o que também tem sido associada com a regulação, produção e manutenção dos neurônios através do aumento da produção de fator de crescimento, o qual é um potente fator trófico e de sobrevivência dos neurônios colinérgicos, particularmente daqueles que consistentemente afetam a DA(MAPSTONE et al., 2014).

Portanto, estes dez marcadores revelam a quebra das membranas celulares neurais em indivíduos com tendência a fenoconversão de um estado cognitivo intacto para um estado de comprometimento cognitivo leve ou a DA e podem marcar a transição entre os estados pré-clínicos com disfunção sináptica e neurodegeneração precoce que dá origem a alterações cognitivas sutis. A maioria das abordagens com base em fluido biomarcador focaram no peptídeo beta amilóide e na fosforilação da proteína TAU, mas ainda não está exatamente claro o que está causando as alterações lipídicas no plasma, por isso, os biomarcadores sanguíneos ainda precisam passar por testes clínicos mais específicos para sua comprovação (MAPSTONE et al., 2014). 


\section{CONCLUSÕES}

A DA é um transtorno neurodegenerativo crônico e progressivo que acomete principalmente pacientes idosos, mas ainda não se sabe ao certo sua fisiopatologia. Atualmente existem apenas evidências histopatológicas e hipóteses como a perda do neurotransmissor colinérgico, a deposição do peptídeo beta-amilóide, formando as placas senis, a formação de emaranhados neurofibrilares contendo a proteína TAU, mecanismos genéticos e inflamatórios.

Em relação aos tratamentos farmacológicos existem poucas classes disponíveis atualmente para uso e a maioria desses medicamentos não revertem a neurodegeneração, apenas promovem um alívio temporário dos sintomas. No entanto, vários testes clínicos estão sendo realizados em busca de um medicamento que possa ser seguro, eficaz e que reverta a neurodegeneração e promova alívio dos sintomas. Muitas destas substâncias poderão ser utilizadas futuramente como novos tratamentos, porém, o tratamento da DA ainda é um desafio, uma vez que não se sabe como se inicia, dificultando a reversão da neurodegeneração e, consequentemente, os sintomas decorrentes.

No entanto, ainda são necessários mais estudos clínicos para avaliar o uso terapêutico destas drogas para o tratamento da DA, bem como o diagnóstico precoce da doença. Pois, este aliado ao uso de medicamentos pode prevenir a piora progressiva da DAquando esta não é tratada.

\section{REFERÊNCIAS}

ARAUJO SR \& PONDÉ MP. Eficácia da memantina na doença de Alzheimer em seus estágios moderado a grave. J. Bras. Psiquiatr. 55(2): 148 - 153, 2006.

ASHRAF GM, TABREZ S, JABIR NR, FIROZ CK, AHMAD S, HASSAN I, ALEIXIOU A, KAMAL MA. An Overview on Global trendsin nanotechnological approaches for Alzheimer therapy. CurrDrug Metab.16(8): 719-27, 2015.

BRUCKI SMD, MAGALDI RM, MORILLO LS, CARVALHO I, PERROCO TR, BOTTINO CMC, JACOB FILHO W, NITRINI R. Demências - enfoque multidisciplinar: das bases fisiopatológicas ao diagnóstico e tratamento. 1. Ed. São Paulo: Ed. Atheneu, 2011. 180 p.

CAVALCANTI JLS \& ENGELHARDT E. Aspectos da fisiopatologia da Doença de Alzheimer esporádica. Rev Bras Neurol. 48(4): 21 - 29, 2012.

CLARK MA, FINKEL R, REY JA \& WHALEN K. Farmacologia llustrada. 5. Ed. Porto Alegre: Ed. Artmed, 2013. 47-52 p. 
CRAMER P. E., CIRRITO JR, WESSON D.W., LEE C.Y., KARLO J.C., ZINN A.E., CASALI B.T., RESTIVO J.L., GOEBEL W.D., JAMES M.J., BRUNDEN K.R., WILSON D.A., LANDRETH G.E. ApoE-Directed Therapeutics Rapidly Clear $\beta$-Amyloid and Reverse Deficits in AD Mouse Models. Science. 335(6075): 1503 - 1506, 2012.

DOUAUD G., REFSUM H., DE JAGER C.A., JACOBY R., NICHOLS T.E., SMITH S.M., SMITH A.D. Preventing Alzheimer's disease-related gray matter atrophy by B-vitamin treatment. Proc Natl Acad SciU SA. 110(23): 9523 - 9528, 2013.

DOODY R.S., RAMAN R., FARLOW M., IWATSUBO T., VELLAS B., JOFFE S., KIEBURTZ K., HE F., SUN X., THOMAS R.G, AISEN P.S. A Phase 3 Trial of Semagacestat for Treatment of Alzheimer's Disease. N Engl J Med. 369(4): 341 - 350, 2013.

EGEFJORD L., GEJL M., MØLLER A., BRÆNDGAARD H., GOTTRUP H., ANTROPOVA O., MØLLER N., POULSEN H.E., GJEDDE A., BROCK B., RUNGBY J. Effects of liraglutide on neurodegeneration, blood flow and cognition in Alzheimer's disease - protocol for a controlled, randomized double-blinded trial. Effects of liraglutide on neurodegeneration, blood flow and cognition in Alzheimer's disease - protocol for a controlled, randomizeddouble-blinded trial. Dan Med J. 59(10): A4519, 2012.

ENGELHARDT E., BRUCKI S.M.T., CAVALCANTI J.L.S., FORLENZA O.V. Tratamento da doença de Alzheimer. Rev. Neuropsiquiatria. 63(4): 1104-1112, 2005.

FORLENZA V. O. Tratamento farmacológico da doença de Alzheimer. Rev. Psiquiatr. Clín. 32(3): 137 - 148, 2005.

FORLIN, C. Mal de Alzheimer. 2010. Disponível em: <http://www.artigonal.com/ medicina-artigos/mal-de-alzheimer-2103890.html>. Acesso em: 01 set. de 2013.

GUTIERREZ B.A.O, SILVA H.S da, GUIMARAES C., CAMPINO A.C. Impacto econômico da doença de Alzheimer no Brasil: é possível melhorar a assistência e reduzir custos? Ciênc. Saúde coletiva. 19(11): 4479 - 4486, 2014.

GUZEN F.P. \& CAVALCANTI J.R.L.P. Influência das proteínas beta amiloide e TAU na doença de Alzheimer. Facene/Famene. 10(1): 57 -60, 2012.

HUEB T. Doença de Alzheimer/Alzheimer's Disease. RBM. 65(4): 90 - 95, 2008. 
INOUYE K \& OLIVEIRA G.H. Avaliação crítica do tratamento farmacológico atual para doenças de Alzheimer. Infarma. 15(11-12): 80 - 83, 2004.

LANDEN J.W., ZHAO Q., COHEN S., BORRIE M., WOODWARD M., BILLING C.B. JR, BALES K., ALVEY C., MCCUSH F., YANG J., KUPIEC J.W., BEDNAR M.M. Safety and pharmacology of a single intravenous dose of ponezumab in subjects with mild-tomoderate. Alzheimer disease: a phase I, randomized, lacebo-controlled, double-blind, dose-escalation study. Clinica de neurofarmacologia. 36(1): 14 - 23, 2013.

LOBATO L.M.C.L. A Nefropatia na Polineuropatia Amiloidótica Familiar de Tipo Português (TTR V30M). 2004. Porto. 201 p. Tese (Doutor em Ciências Médicas), Instituto de Ciências Biomédicas de Abel Salazar - Universidade do Porto. Porto.

MAPSTONE M., CHEEMA A.K., FIANDACA M.S., ZHONG X., MHYRE T.R., MACARTHUR L.H., HALL W.J., FISHER S.G., PETERSON D.R., HALEY J.M., NAZAR M.D., RICH S.A., BERLAU D.J., PELTZ C.B., TAN M.T., KAWAS C.H., FEDEROFF H.J. Plasma phospholipids identify antecedent memory impairment in older adults. Nat med. 20(4): $415-418,2014$.

MONTEIRO M.R., KANDRATAVICIUS L. \& LEITE J.P. O papel das proteínas do citoesqueleto na fisiologia celular normal e em condições patológicas. J. epilepsy clin. Neurophysiol. 17(1): 17-23, 2011.

OJOPI E.P.B., BERTONCINI A.B. \& NETO E.D. Apolipoproteina E e a Doença de Alzheimer. Rev. Psiq. Clín. 31(1): 26 -33, 2004.

PAULA V.J.R. de, GUIMARÃES F.M. \& FORLENZA O.V. Papel da proteína Tau na fisiopatologia da demência frontotemporal. Rev. Psiquiatr. Clín. 36(5): 197 - 202, 2009.

PEREIRA P.M.C.M. Doença de Alzheimer: perspetivas de tratamento. 2013. Covilhã. 38 p. Dissertação (Mestrado em medicina), Universidade da Beira Interior. Covilhã.

PINTO A.L.N. Anti-histaminicos H3: Uma nova classe terapêutica. 2012. Porto. 51 p. Dissertação (Mestrado em Ciências Farmacêuticas). Universidade Fernando Pessoa Faculdade Ciências da Saúde. Porto.

REIS G.P., HUBER P.C. \& ALMEIDA W.P. Avaliação do antimicrobiano levofloxacina como inibidor da fibrilogênese do peptídeo $\beta$-amilóide. Reunião Anual da Sociedade Brasileira de Química, 35a, Águas de Lindoia, Brasil, 2012. 
RENGLAND B., LEHMANN W., ABEDINI L., BLENNOW K., KARISSON L., SIOGREN M., WALLIN A., XILINAS M., GOTTFRIES C.G. Treatment of Alzheimer's disease with clioquinol. Dement Geriatr Cogn Disord.12(6):408 - 14, 2001.

SASTRE M., KLOCKGETHER T. \& HENEKA M.T. Contribution of inflammatory processes to Alzheimer's disease: molecular mechanisms. Int J Dev Neurosci. 24(2-3): $167-176,2006$.

SAYEG N. Como diagnosticar e tratar a Doença de Alzheimer. RBM. 69(12): 97 - 109, 2012.

SERENIKI A. \& VITAL M. A doença de Alzheimer: aspectos fisiopatológicos e farmacológicos. Rev. psiquiatr. Rio Gd. Sul. 30(1): 0 - 0, 2008.

SMITH MAC. Doença de Alzheimer. Rev. psiquiatr. São Paulo. 20(2): 120-40, 1999.

SOTO M.E., VAN KAN G.A., NOURHASHEMI F., GILLETTE-GUYONNET S., CESARI M., CANTET C., ROLLAND Y., VELLAS B.. Angiotensin-converting enzyme inhibitors and Alzheimer's disease progression in older adults: results from the Réseau sur la Maladie d'Alzheimer Français cohort. J Am Geriatr Soc. 61(9): 1482 - 1488, 2013

SUN G.Y., XU J., JENSEN M.D., SIMONYI A. Phospholipase A2 in the central nervous system: implications for neurodegenerative diseases. J Lipid Res. 45(2): 205 - 213, 2004.

TUERO G.C. Hipertensión Arterial y enfermedad de Alzheimer. Alzheimer. Real Invest Demenc. 2(45): 30 - 39, 2010. 